\title{
Association of Cytochrome CYP1A1 Gene Polymorphisms and Tobacco Smoking With the Risk of Breast Cancer in Women From Iraq
}

\author{
Hassan M. Naif ${ }^{*}$, Mohammed A. I. Al-Obaide ${ }^{2}$, Hayfa H. Hassani ${ }^{3}$, \\ Abdualghani S. Hamdan ${ }^{4}$ and Zainab S. Kalaf ${ }^{4}$ \\ ${ }^{1}$ Molecular and Medical Biotechnology, College of Biotechnology, Al-Nahrain University, Baghdad, Iraq, ${ }^{2}$ School of Medicine, \\ Texas Tech University Health Sciences Center, Amarillo, TX, United States, ${ }^{3}$ Biology Department, University of Baghdad, \\ Baghdad, Iraq, ${ }^{4} \mathrm{Al}$-Russafa Health Directorate, Ministry of Health, Baghdad, Iraq
}

OPEN ACCESS

Edited by:

Ruixue Huang,

Central South University, China

Reviewed by:

Yue-Wern Huang,

Missouri University of Science and

Technology, United States

Sofia Kottou,

National and Kapodistrian University

of Athens, Greece

*Correspondence:

Hassan M. Naif

drnaifhassan@gmail.com

Specialty section:

This article was submitted to

Environmental Health,

a section of the journal

Frontiers in Public Health

Received: 19 December 2017

Accepted: 12 March 2018

Published: 11 April 2018

Citation:

Naif HM, Al-Obaide MAl, Hassani HH, Hamdan AS and Kalaf ZS (2018) Association of Cytochrome CYP1A1 Gene

Polymorphisms and Tobacco Smoking With the Risk of Breast Cancer in Women From Iraq. Front. Public Health 6:96. doi: 10.3389/fpubh.2018.00096
Background: CYP1A1 gene polymorphisms and tobacco smoking are among several risk factors for various types of cancers, but their influence on breast cancer remains controversial. We analyzed the possible association of CYP1A1 gene polymorphisms and tobacco smoking-related breast cancer in women from Iraq.

Materials and methods: In this case-control study, gene polymorphism of CYP1A1 gene (CYP1A1m1, T6235C and CYP1A1m2, A4889G) of 199 histologically verified breast cancer patients' and 160 cancer-free control women's specimens were performed by using PCR-based restriction fragment length polymorphism.

Results: Three genotype frequencies (TT, TC, and CC) of CYP1A1m1T/C appeared in $16.1,29.6$, and $54.3 \%$ of women with breast cancer, respectively, compared with 41.2, 40, and $18.8 \%$ in the control group, respectively. CYP1A1m1 CC genotype and C allele were significantly associated with increased risks for breast cancer in patients (54.3 and $69 \%$, respectively) compared with controls (18.8 and 39\%, respectively). While the three genotype frequencies (AA, AG, and GG) of CYP1A1m2A/G were detected in 20.1, 31.2, and $48.7 \%$ in patients compared with $46.3,40.6$, and $13.1 \%$ in controls, respectively. The frequency of GG genotypes and G allele was significantly higher in patients (48.7 and $64 \%$, respectively) than in the controls (13.1 and 33\%, respectively). Smoking women having either CC or GG genotypes showed a highly significant association with increased risk of breast cancer [odds ratio $(\mathrm{OR})=1.607,95 \%$ confidence interval $(\mathrm{Cl})$ $0.91-1.64, p=0.0001$, and $\mathrm{OR}, 1.841,95 \% \mathrm{Cl}, 0.88-1.67, p=0.0001$, respectively]. On the other hand, the $T$ and $A$ alleles of predominantly seen in healthy smoking women (83 and $85 \%, p=0.0001$, respectively).

Conclusion: These findings indicated that both $\mathrm{C}$ and $\mathrm{G}$ alleles of CYP1A1m1 and $m 2$ were significantly associated with elevated risk of breast cancer in Iraqi women, while the $T$ and $A$ alleles were predominantly seen in healthy controls which may indicate their protective role. The $\mathrm{C}$ and $\mathrm{G}$ association with breast cancer incidence was more prevalent among tobacco smoking patients. These polymorphisms may be used as biomarkers of breast cancer in women from Iraq.

Keywords: CYP1A1 genotype, breast cancer, smoking, genetic polymorphism, Iraq 


\section{INTRODUCTION}

It is known that a combination of genetic and environmental risk factors such as hypertension, tobacco use, obesity, and exposure to estrogen and polycyclic aromatic hydrocarbons were shown to be involved in breast cancer $(1,2)$. There are multiple risk factors involved in mediating breast cancer such as DNA damage, cell proliferation, and mutation of the estrogen receptor gene as well as reproductive issues (3-6).

Cytochrome P450 (CYP) is a superfamily of enzymes, including CYP1A1, which catalyze several reactions such as drugs, cholesterol, steroid including estrogen and environmental pollutant breakdown and metabolizes several procarcinogens into active human carcinogens $(4,5,7)$. The CYP1A1 gene is thought to be involved in breast cancer because of its role in the metabolism of the polycyclic aromatic hydrocarbons and in the oxidative metabolism of estrogens that might increase the risk of oxidative stress and cancer (8-10). Polymorphisms of the CYP1A1 gene have been associated with increased aryl hydrocarbon hydroxylase activity which in turn may change individual's susceptibility to breast cancer by either increasing risk in women in different parts of the world (10-14), or had no effect on the disease outcome (15-17).

Tobacco smoking is among the main preventable risk factors for several different diseases. The correlation between active tobacco smoking and breast cancer showed an increased risk among women with certain CYP1A1 mutant genotypes $(18,19)$. The interaction between several compounds in tobacco smoke such as polycyclic hydrocarbons and CYP1A1 genotypes has been reported to influence risk of breast cancer (20-24). However, such association needs further investigation of women with breast cancer in Iraq, because of inconclusive reports (25-27).

In Iraq, breast cancer is the most frequently diagnosed malignancy and the first leading cause of cancer death among women where it accounts for one-third of registered cancers (28). The role of CYP1A1m1 (T6235C) and CYP1A1m2 (A4889G) as a risk in smoking women for breast cancer has not been examined in the local population. This work analyzed the genotype distribution and allele frequencies of CYP1A1m1 and CYP1A1m2 variants in Iraqi women with breast cancer. The study also investigated whether the active tobacco smoking status and duration alter the relationship between genotype distribution and the risk of breast cancer in Iraq.

\section{SUBJECTS AND METHODS}

\section{Study Subjects}

This study consisted of 199 women with breast cancer and 160 cancer-free female controls. The histologically confirmed cases of breast cancer were recruited for approximately 2 years, 1 st January 2015-30th January 2017 from Hospitals in Baghdad. The information on the demographic characteristics including medical and reporoductive histories of tobacco smoking for all participants about duration of their current and previous smoking habits. All procedures were conducted in accordance with the ethical standards of the Human Ethics Committee approval provided by the Ministry of Health (No. 6426). A written informed consent was obtained from all study participants after receiving approval of the experimental protocol by the ethics committee according to the Helsinki Declaration.

\section{Search Strategy and Bioinformatics Analyses of CYP1A1 Polymorphisms}

Thorough research was performed using NCBI-Resources, UCSC genome browser, and Ensemble databases. Search terms for the CYP1A1 T6235C ( $m 1)$ and CYP1A1 A4889G ( $m 2)$ polymorphisms and breast cancer risk were combined and included: tobacco smoke, polycyclic aromatic hydrocarbons' cytochrome P4501A1 (CYP1A1: T6235C, rs4646903; A4889G, rs1048943), and breast cancer. Research papers, case studies, and review articles of relevant literature were manually searched to identify additional appropriate analyses.

The genomic criteria of CYP1A $1 m 1$ and $m 2$ gene polymorphisms were searched in Ensemble, UCSC genome browsers, and GenBank databases. Several tools in the databases were used to retrieve and analyze the sequences, identify the strand (forward and/or reverse), flip the strand, and search for a particular sequence. The precise genomic map locations of the identified sequences were verified and updated to hg38 version of human genome sequence assembly by using the Gene Sorter and Table Browser tools of UCSC Genome Bioinformatics database.

\section{Nucleic Acid Isolation and CYP1A1 Genotyping}

Genomic DNA was extracted from whole blood samples of patients and controls using the QIAamp DNA mini Kit (Qiagen, USA) according to the manufacturer's instructions. CYP1A1 genotypes at the $m 1$ and $m 2$ sites were analyzed by PCR-based restriction fragment length polymorphism as described earlier with slight modification $(11,29,30)$. The primers used for $m 1$ sites were M1F 5'-CAGTGAAGAGGTGTAGCCGCT-3' and M1R 5'-TAGGAGTCTTGTCTCATGCCT3' while the primers used for m2 sitewere M2F5'-GGCTATCCTGCTGCAACGGGTGGAA-3' and M2 R5'-CTGTCTCCCTCTGGTTACAGGAAG-3'. The $\mathrm{M} 1 \mathrm{~F}$ and M1R primers generated a product of $340 \mathrm{bp}$, while M2F and M2R generated a 204 bp product. Each PCR reaction mixture $(25 \mu \mathrm{l})$ contained $100 \mathrm{ng}$ template DNA, $0.2 \mu \mathrm{M}$ each primer, $0.2 \mathrm{mM}$ each $\mathrm{dNTP}$, and 1.0 U Taq polymerase (Fermentas, Canada). To amplify the fragments containing $m 1$ and $m 2$ regions, the reaction involved an initial denaturation step of $7 \mathrm{~min}$ at $95^{\circ} \mathrm{C}$, followed by 35 cycles of $30 \mathrm{~s}$ at $95^{\circ} \mathrm{C}, 1 \mathrm{~min}$ at $61^{\circ} \mathrm{C}$ for $m 1\left(63^{\circ} \mathrm{C}\right.$ for $\left.m 2\right) 35 \mathrm{~s}$ at $72^{\circ} \mathrm{C}$ and a final elongation step of $7 \mathrm{~min}$ at $72^{\circ} \mathrm{C}$. The restriction enzyme Msp1 (Fermentas, Canada) was used to distinguish the $m 1$ polymorphism as gain of an Msp1 restriction site occurs in the polymorphic allele. The wild-type $m 1$ allele shows a single band representing the entire $340 \mathrm{bp}$ fragment and variant allele results in two fragments of 200 and 140 bp. The restriction enzyme BsrD1 (Fermentas, Canada) was used to distinguish the $m 2$ polymorphism from the same 204 bp product in two different reactions. The cleavage sites were lost in the case of the $m 2$ mutations and resulted in a single band, whereas the wild-type $m 2$ alleles generated 149 and 
55 bp bands. The restriction-digested products were analyzed by electrophoresis on a $3 \%$ agarose gel containing ethidium bromide and visualized under a UV illuminator.

\section{Statistical Analyses}

The Hardy-Weinberg (HW) equilibrium was tested using chi-squared $\left(\chi^{2}\right)$ statistics for the goodness-of-fit (1 degree of freedom) between cases and controls. A multivariate analysis using the logistic regression was used to obtain the adjusted crude odds ratio (OR) with a $95 \%$ confidence interval (CI) and to assess the associations between variables of the CYP1A1 m1 and $m 2$ genotypes between breast cancer cases, control group and smoking status. Covariates include age, smoking duration, and postmenopausal and familial history. For all statistical tests, the level of significance was two-sided at $p<0.05$. All of the statistical analyses were performed with Statistical Analysis System software V.8 (SAS Institute, Cary, NC, USA).

\section{RESULTS}

\section{Genomic Context of CYP1A1 Gene and the $m 1$ and $m 2$ Polymorphisms}

The human CYP1A1 locus is mapped in the negative strand of the long arm of chromosome 15 at 15q24.1, which occupies genomic space of 6,069 nucleotides at chr15: 74719542-74725610. This region is mapped in the chromosome 15-NC_000015.10 region that also contains CYP1A2 on the forward strand (Figure 1). Careful analysis of the two polymorphisms of CYP1A1, $m 1$ and $m 2$, in the databases showed that $m 1$ (also known A4889G) has SNP ID: rs1048943 with five synonyms, rs52810784, rs17861092, rs3188998, rs386513458, and VAR_001243. Whereas, $m 2$, also known T6235C has SNP ID: rs4646903 of three synonyms, rs116877783, rs5030838, and rs17861083. The wild allele of $m 1$ codes isoleucine (I) or ancestral phenylalanine (F), while mutant $m 1$ allele leads to missense mutation resulting in an isoleucine (I) change to valine (V). Allele $m 1$ is mapped at chr15:74720644, which has four alleles (T/A/C/G). Genotype $m 2$ is the downstream gene variant which is mapped at chr15:74719300, with three alleles (A/G/T).

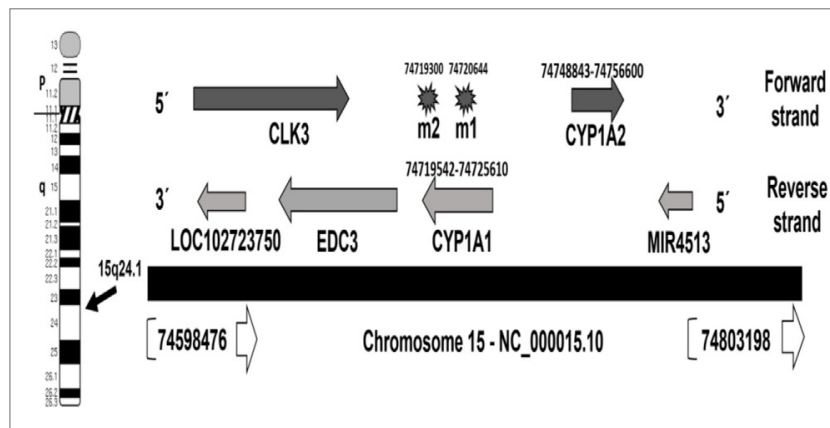

FIGURE 1 | Map locations of CYP1A1 locus and $m 1$ and $m 2$ polymorphisms on chromosome 15-NC_000015.10 region. The locations are updated to hg38 human genome assembly release (31).

\section{Demographic Characteristics of the Study Subjects}

This study included 199 women with breast cancer and 160 cancer-free controls. Table $\mathbf{1}$ shows the demographic and clinical characteristics of those subjects. There was no significant differences $(p=328)$ noted among patients $(48.6 \pm 2.0$ years $)$ and the healthy control group $(47.8 \pm 2.0$ years $)$ on the age risk factor. Whereas only the mean duration of smoking showed a significant difference ( $t$-test, $p=0.029$ ) between smoking women with breast cancer $(30.1 \pm 10.2$ years $)$ and the control group $(21.4 \pm 9.9$ years $)$. This may indicate that a longer smoking period may contribute to susceptible of women to breast carcinogenesis. All cancer patients were confirmed to have invasive ductal or lobular carcinoma by histopathology testing. The percentage of postmenopausal breast cancer patients was $46.7 \%$ which is very similar to the postmenopausal percentage of controls, $44.4 \%$. This excludes the effect of estrogen exposure in our patient population as a significant factor.

\section{Genotyping of CYP1A1m1 and CYP1A1m2 Polymorphisms in Control and Breast Cancer Individuals}

The results of genotype distribution of CYP1A1m1T/C and $C Y P 1 A 1 m 2 A / G$ displayed three genotypes with variable ratios in women with breast cancer and in the control group (Table 2). These results showed that $54.3 \%$ of women with breast cancer were carriers of CC mutant genotypes of CYP1A1m1, which was significantly higher than that observed in the control group $(18.8 \%)(\mathrm{OR}=1.405,95 \% \mathrm{CI}=0.89-1.63, p=0.0083)$. Similarly, a highly significant difference was observed with the GG genotype of CYP1A1m2 being prevalent in $48.7 \%$ of breast cancer patients and only $13.1 \%$ of the control group $(\mathrm{OR}=1.379,95 \%$

TABLE 1 | Demographic characteristics of women with breast cancer (patients) and healthy controls.

\begin{tabular}{|c|c|c|}
\hline Parameter & $\begin{array}{l}\text { Patients (\%) } \\
(n=199)\end{array}$ & $\begin{array}{c}\text { Controls (\%) } \\
\quad(n=160)\end{array}$ \\
\hline
\end{tabular}

\section{Age (years)}

$\leq 40$

$41-45$

46-50

$65(32.7)$

$42(26.3)$

67 (41.9)

0.396 NS

Smoking status

Non-smoker

90 (45.2)

51 (31.9)

Noner

$91(45.7)$

$82(51.3)$

$0.081 \mathrm{NS}$

Current

Former

Mean years smoked

88 (44.2)

$20(10.1)$

$(30.1 \pm 10.2)$

63 (39.4)

$15(9.4)$

$0.095 \mathrm{NS}$

Histological type

Invasive ductal carcinoma

Invasive lobular carcinoma

$91(45.7)$

$108(54.3)$

Postmenopausal status

93 (46.7)

NA

NA

$71(44.4)$

0.612 NS

Family history

First-degree relative with breast cancer

${ }^{*} p<0.05 ;$ NS, non-significant; $n$, number of patients = 199 and number of controls = 160; NA, not applicable 
TABLE 2 | Association between the CYP1A1m1 and CYP1A1m2 genotype and allele frequencies and breast cancer risk among patients and in the healthy controls.

\begin{tabular}{ccccc}
\hline Genotype & $\begin{array}{c}\text { Patients } \\
(\%)\end{array}$ & $\begin{array}{c}\text { Controls } \\
(\%)\end{array}$ & $\chi^{2}$ (p-value) & OR $(95 \% \mathrm{Cl})$ \\
\hline
\end{tabular}

CYP1A1m1 (T6235C)

$w 1 / w 1^{\mathrm{a}}(\mathrm{TT}) \quad 32(16.1 \%) \quad 66(41.3 \%) \quad 8.521^{\star *}(0.0027) \quad 1.176(0.92-1.62)$

$w 1 / m 1^{\mathrm{a}}(\mathrm{TC}) \quad 59(29.7 \%) \quad 64(40.0 \%) \quad 4.277^{*}(0.0431) \quad 0.688(0.87-1.60)$

$m 1 / m 1^{\text {b }}(\mathrm{CC}) \quad 108(54.3 \%) \quad 30(18.8 \%) \quad 9.075^{\star \star}(0.0083) \quad 1.405(0.89-1.63)$

Alleles frequency

$\begin{array}{lllll}T & 31 \% & 61 \% & 10.15^{\star *}(0.0002) & 0.28(0.21-0.39)\end{array}$

C $\quad 69 \% \quad 39 \% \quad 11.16^{\star \star}(0.0002) \quad 3.53(2.59-4.81)$

\section{CYP1A1m2 (A4889G)}

$w 2 / w 2^{a}(A A) \quad 40(20.1 \%) \quad 74(46.3 \%) \quad 7.933^{\star *}(0.0097) \quad 1.085(0.92-1.92)$

$w 2 / m 2^{a}(\mathrm{AG}) \quad 62(31.2 \%) \quad 65(40.6 \%) \quad 5.281^{*}(0.0259) \quad 0.652(0.92-1.63)$

$\mathrm{m} 2 / \mathrm{m}^{\mathrm{b}}(\mathrm{GG}) \quad 97(48.7 \%) \quad 21(13.1 \%) \quad 10.26^{\star \star}(0.0002) \quad 1.379(0.88-1.67)$

\section{Alleles frequency}

A $\quad 36 \% \quad 67 \% \quad 11.47(0.0002) \quad 0.40(0.29-0.55)$

G $\quad 64 \% \quad 33 \% \quad 13.68^{\star \star}(0.0001) \quad 3.59(2.75-5.40)$

$W^{a}$ refers to a wild-type genotype; $m^{b}$ refers to a mutant genotype.

$\chi^{2}$ test for comparison between patients and controls.

${ }^{*} p \leq 0.05$.

${ }^{* *} p \leq 0.01$.

OR, odds ratio; $95 \% \mathrm{Cl}$, 95\% confidence interval.

Total number of patients $=199$ and the total number of controls $=160$.

$\mathrm{CI}=0.88-1.67, p=0.0002)$. The heterozygous mutant genotypes for both $m 1$ and $m 2$ genes had significant differences between patients and controls $(\mathrm{OR}=0.688,95 \% \mathrm{CI}=0.87-160, p=0.0431$ and $\mathrm{OR}=0.652,95 \% \mathrm{CI}=0.92-163, p=0.0259$ ), respectively. On the other hand, the homozygous wild genotypes for $m 1$ (TT) and $m 2$ (AA) were significantly higher in the control groups $(\mathrm{OR}=1.176,95 \% \mathrm{CI}=0.92-1.62, p=0.0027$ and $\mathrm{OR}=1.085$, 95\% CI: $0.92-1.92, p=0.0097$, respectively). This may reflect the protective role of the $\mathrm{T}(61 \%$; OR $=0.28,95 \% \mathrm{CI}=0.21-0.39$, $p=0.0002)$ and $\mathrm{A}(67 \% ; \mathrm{OR}=0.40,95 \% \mathrm{CI}=0.29-0.55$, $p=0.0002$ ) alleles in the normal population against susceptibility to breast cancer. The $\mathrm{C}$ and $\mathrm{G}$ allele frequencies were higher (69 and 64\%, OR $=3.53,95 \% \mathrm{CI}=2.59-4.81, p=0.0002$ and $\mathrm{OR}=3.59,95 \% \mathrm{CI}=2.0 .75-5.40, p=0.0001$, respectively) in breast cancer patients (Table 2).

\section{Prevalence of CYP1A1 Polymorphisms in Smoker Patients and Healthy Controls}

The influence of tobacco smoking on the distribution of $C Y P 1 A 1 m 1$ and $m 2$ genotypes in both groups-patients and controls-revealed that CYP1A1m1/m1 mutant CC genotype was significantly elevated in smoking women with breast cancer (75.9\%) compared with the control group (10.3\%) (OR $=1.607$, 95\% CI $=0.91-1.64, p=0.0001$ ) (Table 3). Similarly, the CYP1A1m2/m2 mutant GG genotype was significantly higher in smoking women $(83.4 \%)$ than the control group $(7.7 \%)$ $(\mathrm{OR}=1.841,95 \% \mathrm{CI}=0.88-1.94, p=0.0001)$. On the other hand, results of both $m 1$ and $m 2$ homozygous wild TT and AA genotypes were higher in control group women who smoked, 75.6 and $78.2 \%$ compared with women with breast cancer (4.6 and 3.7\%) $(\mathrm{OR}=1.659,95 \% \mathrm{CI}=0.88-1.64, p=0.0001$ and $\mathrm{OR}=1.702$,
TABLE 3 Association of tobacco smoking on the CYP1A1m1 and CYP1A1m2 genotype and allele frequencies among women with breast cancer (patients) and healthy controls.

\begin{tabular}{|c|c|c|c|c|}
\hline \multirow[t]{2}{*}{ Genotype } & \multicolumn{2}{|c|}{ Smoking groups } & \multirow[t]{2}{*}{$\chi^{2}$ (p-value) } & \multirow[t]{2}{*}{ OR $(95 \% \mathrm{Cl})$} \\
\hline & $\begin{array}{c}\text { Patients } \\
(\%) \\
(n=108)\end{array}$ & $\begin{array}{c}\text { Controls } \\
(\%) \\
(n=78)\end{array}$ & & \\
\hline
\end{tabular}

\section{CYP1A1m1 (T6235C)}

$W 1 / W 1^{\mathrm{a}}(\mathrm{TT}) \quad 5(4.6 \%) \quad 59(75.6 \%) \quad 12.866$ ** $(0.0001) \quad 1.659(0.88-1.64)$ $w 1 / m 1^{\mathrm{a}}(\mathrm{TC}) \quad 21(19.4 \%) \quad 11(14.1 \%) \quad 1.935 \mathrm{NS}(0.098) \quad 0.173(0.86-1.62)$ $m 1 / m 1^{\text {b }}(\mathrm{CC}) \quad 82(75.9 \%) \quad 8(10.3 \%) \quad 12.257^{\star \star}(0.0001) \quad 1.607(0.91-1.64)$

$\begin{array}{lllll}\text { Alleles frequency } & & & & \\ \mathrm{T} & 14 \% & 83 \% & 17.5^{\star \star}(0.0002) & 0.40(0.21-0.62) \\ \mathrm{C} & 86 \% & 17 \% & 17.5^{\star \star}(0.0001) & 8.25(3.27-11,44)\end{array}$

CYP1A1m2 (A4889G)

$w 2 / w 2^{\mathrm{a}}(\mathrm{AA}) \quad 4(3.7 \%) \quad 61(78.2 \%) \quad 12.968^{\star \star}(0.0001) \quad 1.702(0.89-1.83)$ $w 2 / m 2^{\mathrm{a}}(\mathrm{AG}) \quad 14(13.0 \%) \quad 11(14.1 \%) \quad 1.02 \mathrm{NS}(0.1755) \quad 0.033(0.90-1.61)$ $\mathrm{m} 2 / \mathrm{m}^{\mathrm{b}}(\mathrm{GG}) \quad 90(83.3 \%) \quad 6(7.7 \%) \quad 13.416^{\star \star}(0.0001) \quad 1.841(0.88-1.94)$

Alleles frequency

A $20 \% \quad 85 \% \quad 21.0^{\star *}(0.0001) \quad 0.2(0.11-1.43)$

$\mathrm{G} \quad 80 \% \quad 15 \% \quad 21.0^{\star *}(0.0001) \quad 9.91(4.35-16.41)$

$w^{a}$ refers to a wild-type genotype; $m^{b}$ refers to a mutant genotype.

${ }^{* *} p<0.01$.

NS, non-significant; OR, odds ratio; $95 \% \mathrm{Cl}$, 95\% confidence interval; $n$, number of smoking patients $=108$ (number includes current and former smokers), number of non-smoking patients $=91$, and number of smoking controls $=78$.

TABLE 4 | Association of smoking risk with CYP1A1 $m 1$ and CYP1A1m2 genotype distribution among women with breast cancer (patients only).

\begin{tabular}{|c|c|c|c|c|}
\hline Genotype & $\begin{array}{c}\text { Smokers (\%) } \\
(n=108)\end{array}$ & $\begin{array}{c}\text { Non-smokers } \\
(\%)(n=91)\end{array}$ & $p$-Value & OR $(95 \% \mathrm{Cl})$ \\
\hline \multicolumn{5}{|c|}{ CYP1A1m1 genotype } \\
\hline$w 1 / w 1^{\mathrm{a}}(\mathrm{TT})$ & $5(4.6 \%)$ & 31 (34.0\%) & $0.0001^{* *}$ & $1.483(0.89-1.61)$ \\
\hline$m 1 / m 1^{b}(\mathrm{CC})$ & 82 (75.9\%) & 20 (21.9\%) & $0.0001^{\star \star}$ & $1.802(0.91-1.94)$ \\
\hline \multicolumn{5}{|c|}{ CYP1A1m2 genotype } \\
\hline$w 2 / w 2^{a}(\mathrm{AA})$ & $4(3.7 \%)$ & 35 (38.5\%) & $0.0001^{\star *}$ & $1.577(0.87-1.63)$ \\
\hline$m 2 / m 2^{b}$ (GG) & 90 (83.3\%) & 17 (18.7\%) & $0.0001^{\star *}$ & $1.893(0.90-1.96)$ \\
\hline
\end{tabular}

$W^{a}$ refers to a wild-type genotype; $m^{b}$ refers to a mutant genotype.

OR, odds ratio; $95 \% \mathrm{Cl}$, 95\% confidence interval for comparison between smokers and non-smoker patients.

${ }^{* *} p<0.01$.

Total number of smoking ( $n=108$, number includes current and former smokers) and non-smoker patients $(n=91)$.

95\% CI $=0.89-1.83, p=0.0001$, respectively). Similar patterns of $\mathrm{C}$ and $\mathrm{G}$ allele frequencies were also obtained among smoking patients (86 and 90\%) [OR $=8.25$ (3.27-11.44), $p=0.0002$ and OR $=9.91$ (4.35-16.41), respectively] (Table 3).

\section{Interaction Between Tobacco Smoking and the CYP1A1 Polymorphisms in Patients}

The risk of breast cancer related CYP1A $1 \mathrm{~m} 1$ and $m 2$ polymorphisms were ascertained between smoking and non-smoking patients (Table 4). The results showed that CYP1A1m1/m1 CC mutant genotype in smokers resulted in a greater risk for breast 
cancer (75.9\%), than in non-smoking patients (21.9\%) (OR: 1.802, 95\% CI: $0.91-1.94, p=0.0001)$. By contrast, the non-smoking patients carrying the homozygous wild TT genotype were more frequent $(34 \%)$ than the smoking breast cancer patients $(4.6 \%)$ $(\mathrm{OR}=1.483,95 \% \mathrm{CI}=0.89-1.61, p=0.0001)$. Similarly, the CYP1A1m2 genotype distribution showed that mutant GG genotype in smoking patients was at a higher risk for breast cancer (83.3\%) in comparison with the same genotype in non-smoking patients $(18.7 \%)(\mathrm{OR}=1.893 ; 95 \% \mathrm{CI}=0.90-1.96, p=0.0001)$. While the homozygous wild-type AA genotype was more prevalent in non-smoking breast cancer patients (38.5\%) than those in the smoking breast cancer patients $(3.7 \%)(\mathrm{OR}=1.577,95 \%$ $\mathrm{CI}=0.87-1.63, p=0.0001)$.

\section{DISCUSSION}

In this case-control study, we investigated the correlation between tobacco smoking and gene polymorphisms of CYP1A1m1 T6345C and CYP1A1m2 A4889G with breast cancer risk in women from Iraq. The results demonstrated that gene polymorphisms of both CYP1A1m1 CC and CYP1A1m2 GG mutant genotypes and C, G allele frequencies were significantly associated with a higher risk for breast cancer when compared with healthy controls. The patient and control groups were in HW equilibrium at both CYP1A1m1 and $m 2$. In addition, the interaction between these two polymorphic mutant genotypes and tobacco smoking was strongly correlated with a higher risk of breast cancer among tobacco smoking women in Iraq. This interaction may highlight the significant influence of the CYP1A1 gene polymorphisms on various risk factors, such as tobacco smoking, associated with breast cancer. In general, the CYP1A1 polymorphisms may vary between populations due to differences in race or ethnicity of other populations (32). The polymorphism was evident in many different race and ethnic groups as in African-American $(10,12,15)$, Chinese $(14,16)$, Siberians (17), Canadians (19), Kashmiri and northern Indians (30, 33), Hispanic-non-Hispanic white women (32), Egyptian Arabs [Ref. (34) and this study], and Japanese (35). On the other hand, the TT and AA wild homozygous genotypes as well as $\mathrm{T}$ and $\mathrm{A}$ allele frequencies were significantly higher among the control group which became more prevalent among smoking women with breast cancer. Whether these mutation were protective or harmful, the $m 2$ variant caused a conservative missense and neutral substitution from isoleucine to valine (both aliphatic) at position 426 in the mutant protein which assessed as non-detrimental variant assessed by online service PolyPhen 2 (http://genetics.bwh.harvard.edu/pph2), whereas the $m 1$ variant is considered as a polymorphism variant with a $\mathrm{T}>\mathrm{C}$ substitution at 6235 position in the $3^{\prime}$ non-coding region.

The role of CYP1A1 polymorphisms in breast cancer risk in individuals, however, has been conflicting. Some studies have shown that CYP1A1 polymorphisms are significantly associated with breast cancer risk $(13,34,36)$ consistent with this study. In this study, patients with either $\mathrm{G}$ or $\mathrm{C}$ allele carriers were approximately equally susceptible to breast cancer and the $\mathrm{G}$ and $\mathrm{C}$ allele carriers were under represented in the control group.
These distinguished observations became more obvious among smoking women with breast cancer. Others have reported that the increased risk of breast cancer was only among $G$ mutant allele, but not $\mathrm{C}$ allele carriers (37), and influenced by smoking status $(23,33,38)$. By contrast, others have failed to show such an association (15). Conversely, CYP1A1 gene polymorphisms were associated with a lower risk of breast cancer among Japanese women (35). Moreover, there is no clear association between the CYP1A1 gene polymorphism and breast cancer risk in various parts of the world $(15,16)$. These inconsistent results may be attributed to different sample sizes and ethnic variations among studied populations, as well as exposure to various environmental risk factors. The mechanism of CYP1A1 gene polymorphism effect on cancer induction can be attributed to different pathways such as phase 1 bioactivation of xenobiotics and involvement in the metabolisms of estrogen (converting the metabolites into carcinogens) that leads to elevating the risk of breast cancer (17), lung cancer $(29,30)$, and renal cell cancer (39), or due to the activation of mammary carcinogens by tobacco metabolites (40).

The increased risk of breast cancer among long duration smoking patients in Iraq was associated with both CYP1A1 C and $G$ allele carriers and could also be attributed to recurrent war episodes and the socioeconomic consequences, for example, continuous fear of child abduction during the recent civil unrest, putting additional burden and stress on women in Iraq. In addition, exposure to seasonal dust-storms, inhalation of chemicals, pollution of air by electric generators across urban suburbs and carcinogens which may increase the level of CYP1A1 expression/ mutation in the target tissues. Activation via the aryl hydrocarbon receptor (AhR), by affecting cell signaling pathways, might reflect the role of the AhR in tumor progression $(41,42)$. The mechanism of interaction between AhR and CYP1A1 or CYP2, where both are involved in the metabolism of estrogen which may lead to alteration in steroid levels modulating bioactivation of therapeutic agents and xenobiotics and elevating the risk of breast cancer in smoking women. A larger sample size study including smoking women living in rural areas women is needed to unravel the complex interplay effects between gene polymorphisms and tobacco smoking and to compare between local environmental factors.

\section{CONCLUSION}

Results of this study showed a statistically significant association between the polymorphisms of CYP1A1m1 CC and $m 2$ GG genotypes and $\mathrm{C}$ and $\mathrm{G}$ alleles with the increased risk of women of breast cancer in Iraq. Moreover, this strong association at both genotype and allele levels was exacerbated among tobacco smoking women with breast cancer. On the other hand, the wild TT, AA genotypes, and T and A allele carriers were significantly prevalent among healthy non-cancerous women which persist among smoking women as well. Therefore, $\mathrm{T}$ and A alleles may play a protective role against breast cancer in this population. The predominance of $\mathrm{C}$ and $\mathrm{G}$ alleles among tobacco smoking women with breast cancer may suggest a role in breast cancer 
susceptibility among Iraqi women which could have prognostic implications in breast cancer.

\section{ETHICS STATEMENT}

Ethical clearance was obtained from the Ministry of Health of Iraq Government. The study participants were informed about the study in Arabic, including the purpose of the study. Only those who agreed and signed the informed consent were included. PI ensured partcipants' confidentiality and anonumity as well as no risk or harm involved.

\section{REFERENCES}

1. Anand P, Kunnumakara AB, Sundaram C, Harikumar KB, Tharakan ST, Lai OS, et al. Cancer is a preventable disease that requires major lifestyle changes. Pharm Res (2008) 25:2097-116. doi:10.1007/s11095-008-9690-4

2. Loeb KR, Loeb LA. Significance of multiple mutations in cancer. Carcinogenesis (2000) 21:379-85. doi:10.1093/carcin/21.3.379

3. Hecht SS. Progress and challenges in selected areas of tobacco carcinogenesis. Chem Res Toxicol (2008) 21:160-71. doi:10.1021/tx7002068

4. Mitrunen K, Hirvonen A. Molecular epidemiology of sporadic breast cancer. The role of polymorphic genes involved in oestrogen biosynthesis and metabolism. Mutat Res (2003) 544(1):9-41. doi:10.1016/S1383-5742(03)00016-4

5. de Jong MM, Nolte IM, te Meerman GJ, van der Graaf WT, Oosterwijk JC, Kleibeuker JH, et al. Genes other than BRCA1 and BRCA2 involved in breast cancer susceptibility. J Med Genet (2002) 39(4):225-42. doi:10.1136/jmg.39.4.225

6. Yang B, Jacobs EJ, Gapstur SM, Stevens V, Campbell PT. Active smoking and mortality among colorectal cancer survivors: the Cancer Prevention Study II nutrition cohort. J Clin Oncol (2105) 33:885-93. doi:10.1200/ JCO.2014.58.3831

7. Guengerich FP. Cytochrome p450 and chemical toxicology. Chem Res Toxicol (2008) 21:70-83. doi:10.1021/tx700079z

8. Hukkanen J, Pelkonen O, Hakkola J, Raunio H. Expression and regulation of xenobiotic-metabolizing cytochrome P450 (CYP) enzymes in human lung. Crit Rev Toxicol (2002) 32:391-411. doi:10.1080/20024091064273

9. Snelten CS, Dietz B, Bolton JL. Modulation of estrogen chemical carcinogenesis by botanical supplements used for postmenopausal women's health. Drug Discov Today Dis Mech (2012) 9:1-13. doi:10.1016/j.ddmec.2012.11.001

10. Li Y, Millikan RC, Bell DA, Cui L, Tse CJ, Newman B, et al. Polychlorinated biphenyls, cytochrome P4501A1 (CYP1A1) polymorphisms, and breast cancer risk among African American women and white women in North Carolina: population-based case-control study. Breast Cancer Res (2004) 7: 12-8. doi:10.1186/bcr941

11. Wang H, Wang WJ. Relationship between CYP1A1 polymorphisms and invasion and metastasis of breast cancer. Asian Pac J Trop Med (2013) 6:835-8. doi:10.1016/S1995-7645(13)60148-0

12. Taioli E, Trachman J, Chen X, Toniolo P, Garte SJ. A CYP1A1 restriction fragment length polymorphism is associated with breast cancer in AfricanAmerican women. Cancer Res (1995) 55:3757-8.

13. Ishibe N, Hankinson SE, Colditz GA, Spiegelman D, Willett WC, Speizer FE, et al. Cigarette smoking, cytochrome P450 1A1 polymorphisms, and breast cancer risk in the Nurses' Health Study. Cancer Res (1998) 58:667-71.

14. Shen CY, Li DK, Wy J, Zhang Z, Gao E. Joint effects of the CYP1A1 MspI, ERalpha PvuII, and ERalpha XbaI polymorphisms on the risk of breast cancer: results from a population-based case-control study in Shanghai, China. Cancer Epidemiol Biomarkers Prev (2006) 15(2):342-7. doi:10.1158/10559965.EPI-05-0485

15. Bailey LR, Roodi N, Verrier CS, Yee CJ, Dupont WD, Parl FF. Breast cancer and CYPIA1, GSTM1 and GSTT1 polymorphisms: evidence of a lack of association in Caucasians and African Americans. Cancer Res (1998) 58:65-70.

16. Huang CS, Shen CY, Chang KJ, Hsu SM, Chern HD. Cytochrome P4501A1 polymorphism as a susceptibility factor for breast cancer in postmenopausal Chinese women in Taiwan. Br J Cancer (1999) 80(11):1838-43. doi:10.1038/ sj.bjc. 6690608

\section{AUTHOR CONTRIBUTIONS}

All authors listed have made a substantial, direct, and intellectual contribution to the work and approved it for publication.

\section{ACKNOWLEDGMENTS}

Authors would like to thank Professor Alison Kesson, the University of Sydney for carefully revising and proofreading of this manuscript.

17. Khvostova EP, Pustylnyak VO, Gulyaeva LF. Genetic polymorphism of estrogen metabolizing enzymes in Siberian women with breast cancer. Genet Test Mol Biomarkers (2012) 16(3):167-73. doi:10.1089/gtmb.2011.0131

18. Verde Z, Santiago C, Chicharro LM, Reinoso-Barbero L, Tejerina A, Bandrés F, et al. Effect of genetic polymorphisms and long-term tobacco exposure on the risk of breast cancer. Int J Mol Sci (2016) 17:1726-37. doi:10.3390/ ijms17101726

19. Cotterchio M, Mirea L, Ozcelik H, Kreiger N. Active cigarette smoking, variants in carcinogen metabolism genes and breast cancer risk among preand post-menopausal women in Ontario, Canada. Breast J (2014) 20:468-80. doi:10.1111/tbj.12304

20. Terry PD, Rohan TE. Cigarette smoking and the risk of breast cancer in women: a review of the literature. Cancer Epidemiol Biomarkers Prev (2002) 11:953-71.

21. Basham VM, Pharoah PDP, Healey CS, Luben RN, Day NE, Easton DF, et al. Polymorphisms in CYP1A1 and smoking: no association with breast cancer risk. Carcinogenesis (2001) 22:1797-800. doi:10.1093/carcin/22.11.1797

22. Reynolds P. Smoking and breast cancer. JMammary Gland Biol Neoplasia (2013) 18:15-23. doi:10.1007/s10911-012-9269-x

23. Terry PD, Goodman M. Is the association between cigarette smoking and breast cancer modified by genotype? A review of epidemiologic studies and meta-analysis. Cancer Epidemiol Biomarkers Prev (2006) 15:602-11. doi:10.1158/1055-9965.EPI-05-0853

24. Cox DG, Dostal L, Hunter DJ, Le Marchand L, Hoover R, Ziegler RG, et al. $\mathrm{N}$-acetyltransferase 2 polymorphisms, tobacco smoking, and breast cancer risk in the breast and prostate cancer cohort consortium. Am J Epidemiol (2011) 174:1316-22. doi:10.1093/aje/kwr257

25. Baron JA, Newcomb PA, Longnecker MP, Mittendorf R, Storer BE, Clapp RW, et al. Cigarette smoking and breast cancer. Cancer Epidemiol Biomarkers Prev (1996) 5:399-403.

26. Catsburg C, Miller AB, Rohan TE. Active cigarette smoking and risk of breast cancer. Int J Cancer (2015) 136:2204-9. doi:10.1002/ijc.29266

27. Cui Y, Miller AB, Rohan TE. Cigarette smoking and breast cancer risk: update of a prospective cohort study. Breast Cancer Res Treat (2006) 100:293-9. doi:10.1007/s10549-006-9255-3

28. Iraqi Cancer Registry Directorate, Iraqi Cancer Board, Ministry of Health, Republic of Iraq. Iraqi Cancer Registry Annual Report (2014). 1-11.

29. Cascorbi I, Brockmöller J, Roots I. A C4887A polymorphism in exon 7 of human CYP1A1: population frequency, mutation linkages, and impact on lung cancer susceptibility. Cancer Res (1996) 56:4965-9.

30. Shaffi SM, Shah MA, Bhat IA, Koul P, Ahmad SN, Siddiqi MA. CYP1A1 polymorphisms and risk of lung cancer in the ethnic Kashmiri population. Asian Pac J Cancer Prev (2009) 10:651-6.

31. Daly AK. Polymorphic variants of cytochrome p450: relevance to cancer and other diseases. In: James H, editor. Advances in Pharmacology. Ohio, USA: Academic Press, Northeast Ohio Medical University (2015). p. 85-111.

32. Connor AE, Baumgartner KB, Pinkston CM, Boone SD, Baumgartner RN, Hines LM, et al. Response to Conner et al. re: "cigarette smoking and breast cancer risk in hispanic and non-hispanic white women: the breast cancer health disparities study". J Women Health (2017) 26(1):92-3. doi:10.1089/ jwh.2016.6292

33. Singh V, Rastogi N, Sinha A, Kumar A, Mathur N, Singh MP. A study on the association of cytochrome-P450 A1A polymorphism and breast cancer 
risk in North Indian women. Breast Cancer Res Treat (2007) 101(1):73-81. doi:10.1007/s10549-006-9264-2

34. Ezzeldin N, El-Lebedy D, Darwish A, El-Bastawisy A, Hassan M, Abd El-Aziz S, et al. Genetic polymorphisms of human cytochrome P450 CYP1A1 in an Egyptian population and tobacco-induced lung cancer. Genes Environ (2017) 39:7-15. doi:10.1186/s41021-016-0066-4

35. Miyoshi Y, Takahashi Y, Egawa C, Noguchi S. Breast cancer risk associated with CYP1A1 genetic polymorphisms in Japanese women. Breast J (2002) 8(4):209-15. doi:10.1046/j.1524-4741.2002.08404.x

36. Chacko P, Joseph T, Mathew BS, Rajan B, Pillai MR. Role of xenobiotic metabolizing gene polymorphisms in breast cancer susceptibility and treatment outcome. Mutat Res (2005) 581(1-2):153-63. doi:10.1016/j.mrgentox.2004.11.018

37. Oliveria CB, Filho CC, Bossi LS, Lourenco GJ, Costa-Gurgel MS, Lima CS. Association of CYP1A1 A4889G and T6235C polymorphisms with the risk of sporadic breast cancer in Brazilian women. Clinics (2015) 70:680-5. doi:10.6061/clinics/2015(10)04

38. Androutsopoulos VP, Tsatsakis AM, Spandidos DA. Cytochrome P450 CYP1A1: wider roles in cancer progression and prevention. BMC Cancer (2009) 9:187. doi:10.1186/1471-2407-9-187

39. Meng FD, Ma P, Sui CG, Tian X, Jiang YH. Association between cytochrome P4501A1 (CYP1A1) gene polymorphisms and the risk of renal cell carcinoma: a meta-analysis. Sci Rep (2015) 5:8108. doi:10.1038/srep08108
40. White AJ, D’Aloisio AA, Nichols HB, DeRoo LA, Sandler DP. Breast cancer and exposure to tobacco smoke during potential windows of susceptibility Cancer Causes Control (2017) 28(7):667-75. doi:10.1007/s10552-017-0903-1

41. Al-Dhfyan AO, Alhoshani AR, Korashy HM. Aryl hydrocarbon receptor/ cytochrome P4501 pathway mediates breast cancer stem cells expansion through $\beta$-catenin/Akt activation and Pten inhibition. FASEB J (2017) 31(1 Suppl):671.5. doi:10.1186/s12943-016-0570-y

42. Powell JB, Gennifer DG, Sakina EE. The Aryl hydrocarbon receptor: a target for breast cancer therapy. J Cancer Ther (2013) 4(7):1177-86. doi:10.4236/ jct.2013.47137

Conflict of Interest Statement: The authors declare that the research was conducted in the absence of any commercial or financial relationships that could be construed as a potential conflict of interest.

Copyright (c) 2018 Naif, Al-Obaide, Hassani, Hamdan and Kalaf. This is an openaccess article distributed under the terms of the Creative Commons Attribution License (CC BY). The use, distribution or reproduction in other forums is permitted, provided the original author(s) and the copyright owner are credited and that the original publication in this journal is cited, in accordance with accepted academic practice. No use, distribution or reproduction is permitted which does not comply with these terms. 